\title{
Long-term Recording of Hypothalamic GnRH Pulse Generator Activity during Programmed Administration of Progesterone and Estradiol in the Ovariectomized Goat
}

\author{
Tomomi TANAKA, Yuji MORI ${ }^{1)}$ and Kunio HOSHINO \\ Laboratory of Veterinary Reproduction, Tokyo \\ University of Agriculture and Technology \\ Fuchu, Tokyo 183, and ${ }^{1)}$ Laboratory of \\ Veterinary Ethology, The University of \\ Tokyo, Bunkyo-ku, Tokyo 113, Japan
}

\begin{abstract}
Changes in the $\mathrm{GnRH}$ pulse generator activity were examined during the programmed treatment with ovarian steroids, which mimicked endocrine events in the luteal and follicular phases, by recording the hypothalamic multiple unit activity specifically associated with the pulsatile LH secretion (MUA volleys) in ovariectomized goats. The steroidal milieu of the luteal phase was simulated by subcutaneously implanting silastic capsules containing progesterone and estradiol, and that of follicular phase by intravenously infusing estradiol at a gradually increasing infusion-rate after removal of the progesterone capsules. The administration of progesterone alone for 3 days had little influence on MUA volleys, but there was a significant reduction $(p<0.05)$ in the MUA volley frequency following the additional administration of estradiol, which resulted in the low pulse frequency observed in the normal luteal phase. In the mimicked follicular phase the MUA volley frequency was increased from $10.0 \pm 2.9$ to $13.7 \pm 1.9$ volleys $/ 12 \mathrm{~h}$ after the progesterone removal, but then decreased gradually in parallel with an increase in the plasma estradiol concentration. There was no increase in MUA volley frequency during the transition from the basal to the surge mode of LH secretion. These results suggest that the hypothalamic GnRH pulse generator activity is suppressed during the luteal phase by a synergetic action of progesterone and estradiol, and that the acceleration of the GnRH pulse generator activity does not take place during the preovulatory LH surge in the female goat.
\end{abstract}

Key words: GnRH pulse generator, MUA volley, Ovarian steroids, Goat.

(J. Reprod. Dev. 40: 183-188, 1994)

$\mathbf{P}$ ulsatile secretion of gonadotropin-releasing hormone $(\mathrm{GnRH})$ from the median eminence is driven by the neural mechanism so called the $\mathrm{GnRH}$ pulse generator that is thought to reside in the hypothalamus [1, 2]. This pulsatility of GnRH release has been recognized as the key determinant of reproductive function in all mammals examined to date $[3,4]$. In most previous studies,

Accepted for Publication: March 23, 1994 Correspondence: Y. Mori the monitoring of GnRH pulse generator activity has been attempted by statistically detecting the LH pulses in the peripheral circulation or the GnRH pulses in the portal circulation or directly measuring the extracellular fluid [2]. Recently we have demonstrated in ovariectomized goats that the $\mathrm{GnRH}$ pulse generator activity can be assessed electrophysiologically by recording the hypothalamic multiple unit activity (MUA volleys) which is specifically associated with the LH pulses in the peripheral circulation [5-7]. This technique was 
originally established in the monkey [8] and then in the rat [9], and has made possible direct electrophysiologic access to the central component of the neuroendocrine system which regulates reproductive processes in these species.

In the previous study [6], using this technique, we monitored changes in the $\mathrm{GnRH}$ pulse generator activity during the $\mathrm{LH}$ surge induced by estradiol infusion for $16 \mathrm{~h}(3 \mu \mathrm{g} / \mathrm{h}$, i.v.) in ovariectomized goats, and hypothesized that an acceleration of the $\mathrm{GnRH}$ pulse generator is not a prerequisite for the induction of the LH surge. However, since the steroidal milieu in our previous study was far from those in intact female goats, we needed to test the hypothesis with more physiological model in terms of steroidal profiles in the circulation. In the present study, we therefore adopted a programmed administration of progesterone and estradiol, which could mimick endocrine environments during the luteal and follicular phases in ovariectomized goats [10], and examined changes in the $\mathrm{GnRH}$ pulse generator activity by continuously monitoring the hypothalamic MUA volleys.

\section{Materials and Methods}

Long-term ( $>3$ month) ovariectomized Shiba goats were implanted with electrode arrays bilaterally in the arcuate-median eminence region under the halothane anesthesia. The design of the electrodes, procedure for electrode implantation and methods for MUA recording have been described previously [5, 12]. Three animals, from which MUA volleys were recorded consistently, were kept in the Faraday cage where the daylight (12L : 12D) and temprature (23 C) were maintained, and were used for the following experiments.

The method for programmed administration of ovarian steroids has been described elsewhere [10]. In the present study the ovariectomized goats were first implanted subcutaneously with progesterone capsules made of Silastic sheet $(50 \times 75 \mathrm{~mm}$; Dow Corning) for 3 days, then implanted additionally with an estradiol capsule ( $3.35 \mathrm{~mm}$ i.d., $4.65 \mathrm{~mm}$ o.d., $40 \mathrm{~mm}$ long; Dow Corning) for another 3 days, which together reproduced the steroidal milieu during the luteal phase. To mimic luteolysis and the preovulatory increase in estradiol secretion, the progesterone capsules were removed and then es- tradiol solution $(0.54 \mu \mathrm{g} / \mathrm{ml}$ in $0.54 \%$ ethanol saline) was intravenously infused for $36 \mathrm{~h}$ at a gradually increased infusion rate of from $0.5 \mu \mathrm{g} / \mathrm{h}(0 \mathrm{~h})$ to $3.0 \mu \mathrm{g} / \mathrm{h}(36 \mathrm{~h})$. The recording of MUA was commenced about $12 \mathrm{~h}$ before the progesterone implantation and continued for about 10 days except for $1 \mathrm{~min}$ interruptions every $24 \mathrm{~h}$ to change computer files.

Blood samples $(5 \mathrm{ml})$ were collected every $24 \mathrm{~h}$ during the period of progesterone treatment, and every $2 \mathrm{~h}$ for $48 \mathrm{~h}$ from $2 \mathrm{~h}$ before the removal of the progesterone packets. Additionally, $1 \mathrm{ml}$ blood samples were collected every $6 \mathrm{~min}$ for $4 \mathrm{~h}$ on 3 occasions to examine the pulsatility of LH secretion in different steroidal environments.

The plasma concentrations of LH, progesterone and estradiol were measured by radioimmunoassays described elsewhere [13]. Intra- and interassay coefficients of variation were $8.2 \%$ and $18.5 \%$, $10.4 \%$ and $15.1 \%, 8.9 \%$ and $21.6 \%$ for $\mathrm{LH}$, progesterone and estradiol, respectively.

Data are expressed as the mean values $\pm S E M$, and the difference between mean values for the pre-treatment control period and the steroidtreated period was examined by paired $t$-test.

\section{Results}

Constant release of ovarian steroids from the subcutaneous implants maintained the plasma concentrations of progesterone and estradiol at $4.5 \pm$ $0.6 \mathrm{ng} / \mathrm{ml}$ and $5.5 \pm 0.9 \mathrm{pg} / \mathrm{ml}$, respectively, which were within the physiological ranges for these steroids during the luteal phase in intact goats [13].

The relation between the hypothalamic MUA and LH pulses in the peripheral circulation that was seen in the control period was maintained during the periods of treatment with progesterone alone or in combination with estradiol as shown in Fig. 1. The initiation of each $\mathrm{LH}$ pulse was always preceded by the MUA volley regardless of interpulse intervals.

The MUA volley frequency during the period of treatment with progesterone alone was not changed significantly ( $p>0.05)$ as compared to the pre-treatment control period (21.7 \pm 0.3 MUA volleys $/ 12 \mathrm{~h})$, but it declined dramatically $(\mathrm{p}<0.05)$ to $10.7 \pm 0.9$ MUA volleys $/ 12 \mathrm{~h}$ at $36 \mathrm{~h}$ after the additional implantation of the estradiol capsule as shown in Fig. 2. 


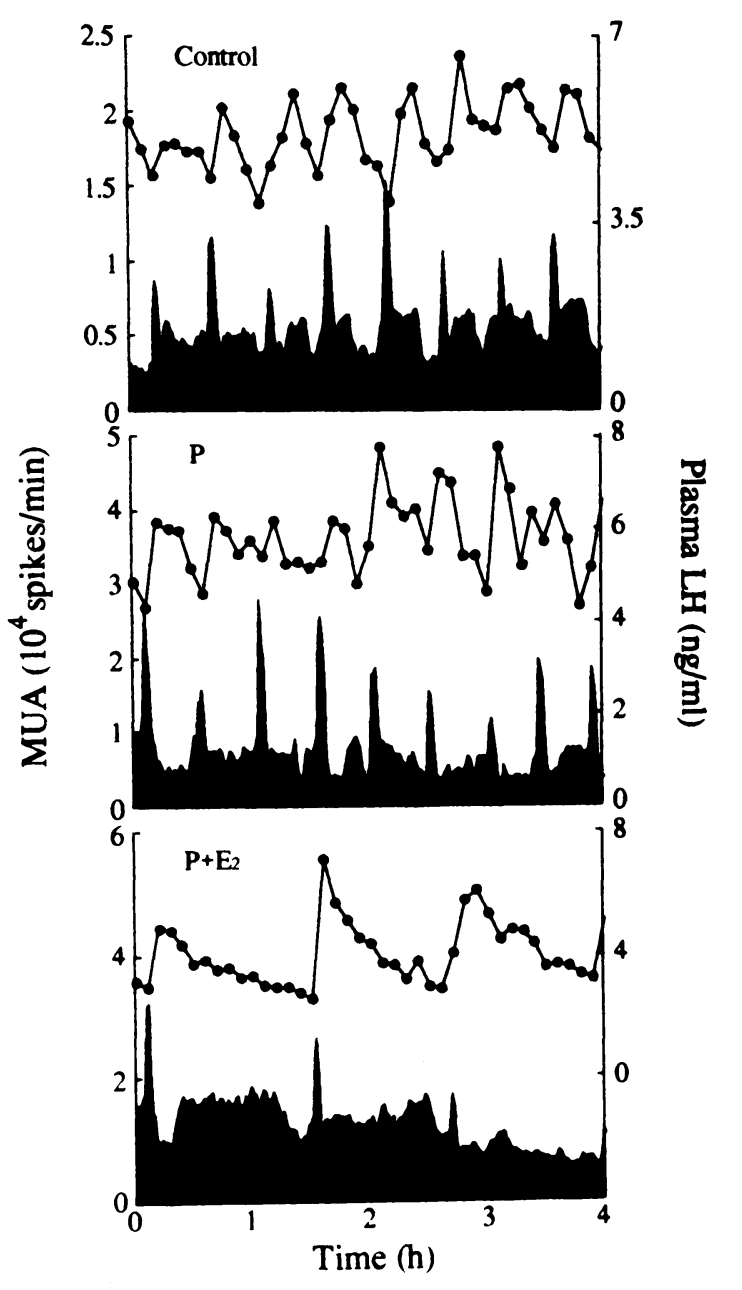

Fig. 1. The relation between MUA volleys and $\mathrm{LH}$ pulses in a representative ovariectomized goat treated with luteal-phase levels of ovarian steroids. Upper, Control period; Middle, Treatment period with progesterone alone (3rd day); Bottom, Combined treatment period with progesterone and estradiol (3rd day). The initiation of each LH pulse was always preceded by an MUA volley regardless of interpulse intervals.

Changes in the MUA volley frequency during the mimicked follicular phase in two goats are shown in relation to the endocrine changes (Fig. 3). Plasma progesterone declined to the basal level $(<1 \mathrm{ng} / \mathrm{ml}$ ) within $6 \mathrm{~h}$ of progesterone withdrawal. The estradiol level, on the other hand, increased gradually and the LH surge was induced 30 (\#04)32 (\#24, \#27) h after the start of estradiol infusion. The MUA volley frequency increased from $10.0 \pm$ 2.9 volleys $/ 12 \mathrm{~h}\left(\mathrm{P}+\mathrm{E}_{2} 3\right.$ day) to $13.7 \pm 1.9$ volleys/ $12 \mathrm{~h}$ after the removal of progesterone, but then

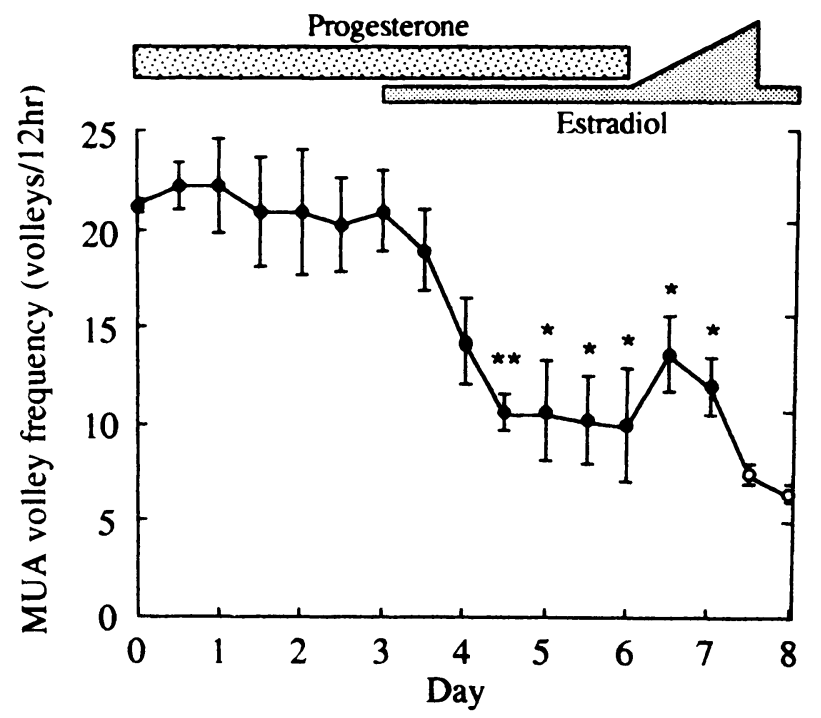

Fig. 2. The effects of ovarian steroids on the frequency of MUA volleys throughout the experimental period in ovariectomized goats. The MUA volley frequency was not changed significantly $(p>0.05)$ during the treatment period with progesterone alone as compared to the control period, but it declined $\left.{ }^{*} \mathrm{p}<0.05,{ }^{* *} \mathrm{p}<0.01\right)$ after the additional treatment with estradiol. Data are expressed as the mean \pm SEM for $3(O)$ or $2(\bigcirc)$ ovariectomized goats. Data obtained from 2 animals were not subjected to the statistical test.

decreased gradually in parallel with an increase in the plasma estradiol concentration (Figs. 2, 3), and regular recurrence of MUA volleys was observed during the LH surge. For the remaining goat, data recorded during the LH surge are missing due to a recording problem.

\section{Discussion}

The present study demonstrated that, in ovariectomized goats, the $\mathrm{GnRH}$ pulse generator activity changed dramatically during the programmed administration of ovarian steroids which mimicked endocrine events in the luteal and follicular phases. Results of the present study have led us to hypothesize that 1) the GnRH pulse generator activity is suppressed by synergetic effects of progesterone and estradiol at luteal phase levels, and 2) the GnRH pulse generator may not be directly involved in the formation of the preovulatory LH surge. The latter hypothesis is also supported by our previous finding in ovariectomized 


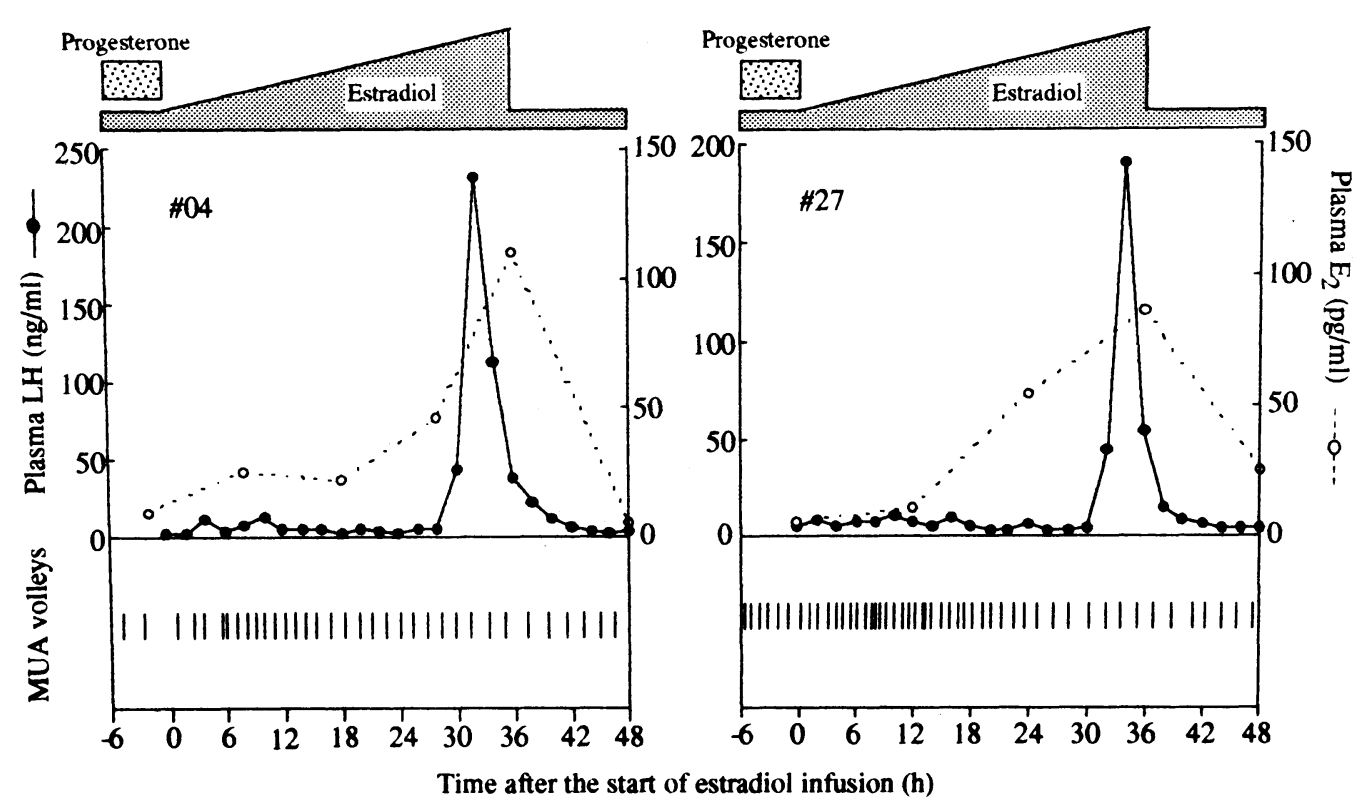

Fig. 3. The appearance of the MUA volleys $(I)$ and the endocrine changes during the mimicked follicular phase in two ovariectomized goats. The plasma estradiol $\left(E_{2}\right)$ level was raised gradually by increasing the rate of infusion of estradiol, which resulted in the induction of the preovulatory-like LH surge. The frequency of the MUA volley increased after progesterone removal but then decreased again in parallel with the increase in estradiol.

goats given constant infusion of estradiol [6].

In ovariectomized ewes, however, the frequency of pulsatile LH secretion was shown to be suppressed by progesterone alone [14], and Karsch et al. [15] reported that this is caused by reduced frequency of pulsatile GnRH secretion into the portal circulation. The reason for this inconsistency with our present results is unclear, though it may be ascribed to differences in the species, the duration of the progesterone treatment or the parameters used to monitor the GnRH pulse generator activity. In previous studies [14, 15] short-term ovariectomized animals were used and progesterone treatment was commenced only 10 days after ovariectomy, whereas we used long-term ( $>3$ months) ovariectomized animals. Therefore, in the former experimental model there might have been some carry-over effects of endogenous estradiol considering the fact that the MUA volley frequency was abruptly suppressed after additional treatment with estradiol at the luteal phase level. This idea is also supported by the previous observation that the pulse frequency of LH secretion was little suppressed by progesterone alone in the long-term ovariectomized ewe [16]. In addition, the frequency of the MUA volley increased after the progesterone withdrawal, indicating that the
GnRH pulse generator activity is also not fully suppressed by low-level estradiol alone. Taken together, the results suggest that progesterone plays a predominant role to hold the activity of the GnRH pulse generator with a synergetic action of basal levels of estradiol which appears to play a rather permissive role during the luteal phase in cycling goats.

The accerelation of MUA volley frequency after the progesterone removal is consistent with the previous observation that the LH pulse frequency increased following luteolysis in cycling goats [11]. In the present study, however, this increase in MUA volley frequency was found to fall off gradually in parallel with the increase in the plasma estradiol level. It has been reported that estradiol treatment greatly diminished the pulsatile secretion of GnRH in the portal circulation of the ewe [15], and the frequency of MUA volleys was shown to decline dramatically following the injection of estradiol in the rhesus monkey [17]. The present results thus support the concept that high levels of estradiol act on the brain to suppress the $\mathrm{GnRH}$ pulse generator activity.

In the present study, the plasma estradiol level was raised gradually to simulate the preovulatory estradiol profile in the follicular phase. This re- 
sulted in the induction of a preovulatory-like $\mathrm{LH}$ surge with a similar latency after the progesterone decline to that seen in cycling females [13], although plasma estradiol reached supraphysiological peak levels which were several times higher than normal preovulatory peaks. The regular recurrence of the MUA volleys continued throughout the artificial follicular phase including the period of the LH surge, and this was consistent with our previous observation at the LH surge induced by constant estradiol infusion in ovariectomized goats [6]. Since we have shown that the LH surge is preceded by the GnRH surge [18] utilizing the intracerebral microdialytic approach [19], the results of our present as well as previous studies have indicated that induction of the GnRH surge is governed by the 'surge generator', another neural mechanism that is different from the GnRH pulse generator. In support of our view, a dramatic decrease in the MUA volley frequency has recently been reported during both the preovula- tory [17] and estradiol-induced LH surges in the rhesus monkey [22].

The present study has demonstrated changes in the $\mathrm{GnRH}$ pulse generator activity in relation to the endocrine environment during the mimicked luteal and follicular phases. However, since our tentative hypotheses are based on the data obtained from ovariectomized animals, it is necessary to establish a system for monitoring the $\mathrm{GnRH}$ pulse generator activity during the estrous cycle in intact goats to know what is happening in nature.

\section{Acknowledgments}

This study was supported in part by grants to Y. M. and T. T. from the Ministry of Education, Science and Culture, Japan. T. Tanaka received a Research fellowship of the Japan Society for the Promotion of Science for Young Scientists.

\section{References}

1. Lincoln DW, Fraser FM, Lincoln GA, Martin GB, McNeilly AS. Hypothalamic pulse generators. Recent Prog Horm Res 1985; 41: 369-419.

2. Levine JE, Bayer-Dantoin AC, Besecke LM, Conagham LA, Leagn SJ, Meredith JM, Strobl FJ, Urban JH, Vogeisong KM, Wolfe AM. Neuroendocrine regulation of the luteinizing hormone-releasing hormone pulse generator in the rat. Recent Prog Horm Res 1991; 47: 97-153.

3. Knobil E. The neuroendocrine control of the menstrual cycle. Recent Prog Horm Res 1980; 36: 53-88.

4. Knobil E, Hotchkiss J. The menstrual cycle and its neuroendocrine control. The Physiology of Reproduction 1988; 2: 1971-1994.

5. Mori $Y$, Nishihara $M$, Tanaka $T$, Shimizu $T$, Yamaguchi M, Takeuchi Y, Hoshino K. Chronic recording of electrophysiological manifestation of the hypothalamic gonadotropin-releasing hormone pulse generator activity in the goat. Neuroendocrinology 1991; 53: 392-395.

6. Tanaka T, Mori Y, Hoshino K. Hypothalamic GnRH pulse generator activity during the estradiol-induced LH surge in ovariectomized goats. Neuroendocrinology 1992; 56: 641-645.

7. Ito K, Tanaka T, Mori Y. Opioid peptidergic control of gonadotropin-releasing hormone pulse generator activity in the ovariectomized goat. Neuroendocrinology 1993; 57: 634-639.

8. Wilson RC, Kesner JS, Kaufman JM, Uemura T,
Akema T, Knobil E. Central electrophysiologic correlates of pulsatile luteinizing hormone secretion in the rhesus monkey. Neuroendocrinology 1984; 39: 256-260.

9. Kimura F, Nishihara $M$, Hiruma $H$, Funabashi $T$. Naloxone increases the frequency of the electrical activity of luteinizing-releasing hormone pulse generator in long-term ovariectomized rats. Neuroendocrinology 1991; 53: 97-102.

10. Mori Y, Takedomi T, Mizomoto Y, Hoshino K. Induction of preovulatory endocrine events by programmed administration of progesterone and estradiol in ovariectomized goats. Jpn J Anim Reprod 1987; 33: 36-40.

11. Kanai Y, Ishikawa N. Pulsatile secretion of luteinizing hormone and plasma levels of ovarian steroids during the estrous cycle in the shiba goat. Jpn J Anim Reprod 1988; 34: 105-110.

12. Mori $Y$, Takeuchi $Y$, Shimada M, Hayashi S, Hoshino K. Stereotaxic approach to hypothalamic nuclei of the Shiba goat with radiographic monitoring. Jpn J Vet Sci 1990; 52: 339-349.

13. Mori Y, Kano Y. Changes in plasma concentration of $\mathrm{LH}$, progesterone and oestradiol in relation to the occurrence of luteolysis, oestrus and time of ovulation in the Shiba goat (Capra hircus). J Reprod Fertil 1984; 72: 223-230.

14. Goodman RL, Karsch FJ. Pulsatile secretion of luteinizing hormone: Differential suppression by 
ovarian steroids. Endocrinology 1980; 107: 12861290.

15. Karsch FJ, Cummins JT, Thomas GB, Clarke IJ. Steroid feedback inhibition of pulsatile secretion of gonadotropin-releasing hormone in the ewe. Biol Reprod 1987; 36: 1207-1218.

16. Martin GB, Scaramuzzi RJ, Henstridge JD. Effects of oestradiol, progesterone and androstenedione on the pulsatile secretion of luteinizing hormone in ovariectomized ewes during spring and autumn. J Endocrinology 1983; 96: 181-193.

17. Kesner JS, Wilson RC, Kaufman JM, Hotchkiss J, Chen Y, Yamamoto H, Pardo RR, Knobil E. Unexpected responses of the hypothalamic gonadotropin-releasing hormone 'pulse generator' to physiological estradiol inputs in the absence of the ovary. Proc Natl Acad Sci 1987; 84: 8745-8749.

18. Manabe $Y$, Yamaguchi M, Tanaka T, Mori Y. Estradiol-induced GnRH surge in ovariectomized goats. J Reprod Dev 1993; 39: 91-96.

19. Yamaguchi $M$, Manabe $Y$, Tanaka T, Mori $Y$,
Hoshino K. Microdialysis measurement of in vivo gonadotropin-releasing hormone secretion in the goat. J Reprod Dev 1993; 38: 143-150.

20. Clarke IJ, Cummins JT. Increased gonadotropinreleasing hormone pulse frequency associated with estrogen-induced luteinizing hormone surges in ovariectomized ewes. Endocrinology 1985; 116: 2376-2383.

21. Caraty A, Locatelli A, Martin GB. Biphasic response in the secretion of gonadotrophin-releasing hormone $(\mathrm{GnRH})$ in ovariectomized ewes injected with oestradiol. J Endocrinol 1989; 123: 375382.

22. O'byrne KT, Thalabard JC, Grosser PM, Wilson RC, Williams CL, Chen MD, Ladendorf D, Hotchkiss J, Knobil E. Radiotelemetric monitoring of hypothalamic gonadotropin-releasing hormone pulse generator activity throughout the menstrual cycle of the rhesus monkey. Endocrinology 1991; 129: 1207-1214. 